\title{
SOME FEATURES OF PROFESSIONAL DEVELOPMENT OF LAW ENFORCEMENT INVESTIGATORS
}

\author{
Vitaly F. Vasyukov \\ Moscow State Institute of International Relations of the Ministry of Foreign Affairs of the Russian Federation, \\ Moscow, Russian Federation; \\ Orel Law Institute of the Ministry of Internal Affairs of Russia Named After V.V. Lukyanov, \\ Orel, Russian Federation
}

\begin{abstract}
Alexey K. Shemetov
Yekaterinburg Branch of Moscow Academy of the Investigative Committee of the Russian Federation, Yekaterinburg, Russian Federation
\end{abstract}

Introduction: in the scientific and methodological literature, a significant number of publications deal with the professional training of various specialists. Most of the works of this kind pay attention to the continuous improvement of the skills of teaching staff. However, there is an acute shortage of the works that reveal the problems of training and growth of specialists in other areas, including the formation and improvement of the official qualities of law enforcement officers. To date, the specialized higher education institutions have been established and are functioning in all the law enforcement agencies, and the professional development programs are successfully operating. However, the experience of organizing activities for the formation and development of the professional qualities of the investigative workers should be generalized, systematized and serve as a basis for further improvement of activities in this direction. Purpose: to generalize and systematize the experience of organizing the professional development of the investigative law enforcement officers, to highlight the features of this process. Methods: during the research, various methods of scientific knowledge were used, including a systematic approach to the study subject, as well as the method of modeling and comparative legal analysis. Results: the paper attempts to identify the features of the process of formation of the personality of a young investigator, the formation and development of the professional qualities of a specialist at various stages, as well as the directions for improving his knowledge, skills and abilities using the specific methods and training tools. Conclusions: summing up the research, the authors come to the conclusion that the system of professional development of the investigative law enforcement officers in its organization should take into account the peculiarities of the formation and development of the professional qualities of specialists in this field, as well as the specifics of the training process, be carried out on an ongoing basis, use the modern tools and methods, as well as the educational technologies.

Key words: law enforcement agencies, investigator, qualification, professional activity, training.

Citation. Vasyukov V.F., Shemetov A.K. Some Features of Professional Development of Law Enforcement Investigators. Legal Concept = Pravovaya paradigma, 2021, vol. 20, no. 2, pp. 100-106. (in Russian). DOI: https:// ธิธ doi.org/10.15688/lc.jvolsu.2021.2.13

Дата поступления статьи: 18.03.2021

ББК 65.291 .6

Дата принятия статьи: 08.04.2021

\section{НЕКОТОРЫЕ ОСОБЕННОСТИ ПОВЫШЕНИЯ КВАЛИФИКАЦИИ СЛЕДОВАТЕЛЕЙ ПРАВООХРАНИТЕЛЬНЫХ ОРГАНОВ}

\section{Виталий Федорович Васюков}

Московский государственный институт международных отношений (университет) МИД России, г. Москва, Российская Федерация;

Орловский юридический институт МВД России им. В.В. Лукьянова, г. Орел, Российская Федерация 


\section{Алексей Константинович Шеметов}

Екатеринбургский филиал Московской академии Следственного комитета Российской Федерации, г. Екатеринбург, Российская Федерация

Введение: в научно-методической литературе значительное количество публикаций посвящено профессиональной подготовке различных специалистов. Большинство работ подобного рода уделяют внимание постоянному совершенствованию навыков педагогических работников. Однако существует острый дефицит работ, вскрывающих проблемы подготовки и роста специалистов в иных сферах, в том числе по формированию и совершенствованию должностных качеств сотрудников правоохранительных органов. На сегодняшний день созданы и функционируют специализированные высшие учебные заведения во всех силовых структурах, успешно работают программы повышения квалификации кадров. Однако опыт организации деятельности по становлению и развитию профессиональных качеств следственных работников должен обобщаться, систематизироваться и служить базой для дальнейшего совершенствования деятельности в указанном направлении. Цель: обобщение и систематизация опыта организации повышения квалификации следственных работников правоохранительных органов, выделение особенностей указанного процесса. Методы: при проведении исследования использовались различные методы научного познания, в том числе системного подхода к предмету изучения, а также метод моделирования и сравнительно-правового анализа. Результаты: в работе предпринята попытка выделения особенностей процесса становления личности молодого следователя, формирования и развития профессиональных качеств специалиста на различных этапах, а также направлений совершенствования его знаний, навыков и умений с использованием конкретных методов и средств обучения. Выводы: подводя итог исследованию, авторы приходят к выводам о том, что система повышения квалификации следственных работников правоохранительных органов при ее организации должна учитывать особенности формирования и развития профессиональных качеств у специалистов указанной сферы, а также специфику процесса обучения, осуществляться на постоянной основе, использовать современные средства и методы, а также образовательные технологии.

Ключевые слова: правоохранительные органы, следователь, квалификация, профессиональная деятельность, обучение.

Цитирование. Васюков В. Ф., Шеметов А. К. Некоторые особенности повышения квалификации следователей правоохранительных органов // Legal Concept = Правовая парадигма. - 2021. - Т. 20, № 2. - C. 100-106. DOI: https://doi.org/10.15688/lc.jvolsu.2021.2.13

\section{Введение}

Использованию современных подходов и методов обучения в высших образовательных учреждениях всегда уделялось достаточное внимание со стороны ученых [1, с. 472; 5; 6]. При этом многими из них выделялись особенности подготовки специалистов различных направлений. Несомненно, определенной спецификой обладает и дополнительное образование в форме повышения квалификации действующих юристов-практиков, оттачивающих собственные навыки в соответствии с потребностями профессии. Именно в этой сфере реализует себя система ведомственных образовательных учреждений в правоохранительных органах Российской Федерации.

При обучении следственных работников в рамках подобных сборов реализуется практико-ориентированный подход, использующий различные сочетания активных и интерактивных технологий.

Значительную нехватку наработок в указанной сфере выявила пандемия коронавируca, переведшая систему обучения в дистанционный формат.

\section{Формирование и развитие профессиональных качеств следственного работника правоохранительных органов}

Повышение квалификации (направленное на овладение навыками, умениями, способностями эффективного выполнения конкретной профессиональной деятельности) должно рассматриваться, на наш взгляд, в качестве непрерывной деятельности самого обучающегося. Этот процесс должен включать не только отдельные сборы, но и давать возможность самому слушателю обращаться к требуемо- 
му для себя материалу. Повышение квалификации практического работника должно сопровождать его в течение всей профессиональной деятельности, соответствовать его уровню на каждом из этапов «профессионального» взросления и роста. Подобного рода деятельность должна осуществляться на принципах многоуровневости, отличаться большей ориентированностью на овладение реальными навыками выполнения практических операций.

Профессиональная квалификация следователя должна рассматриваться как постоянно совершенствующаяся совокупность не только специальных, но и общих знаний, способностей, на которых базируются умения и навыки выполнения профессиональных функций в рамках раскрытия и расследования преступлений на различных этапах.

Наличие многоуровневой системы повышения квалификации следователей должно учитывать различные критерии выделения групп обучаемых, к каждой из которых предъявляются различные требования, используются разные методы обучения и формы учебных занятий.

В профессиональной квалификации традиционно выделяют несколько уровней овладения профессией.

В самом начале профессионального пути специалист после окончания высшего учебного заведения обладает лишь уровнем образованности, достаточным для начала освоения профессиональной деятельности [3, с. 159].

Не вдаваясь в уже давно ведущиеся дискуссии о качестве подготовки специалистов различного уровня высшими заведениями нашей страны, следует отметить, что выпускники образовательных учреждений обладают разным уровнем указанной образованности, дифференцированным набором навыков и способностей выполнения не только специальных, но и общих операций. Указанное обстоятельство, несомненно, должно учитываться при определении форм и методов обучения, используемых на этом этапе «становления» специалиста.

По мнению некоторых специалистов, на начальном этапе следователь даже не обладает профессиональной квалификацией ввиду отсутствия у него минимума профессиональных качеств, требуемых для формирования таковой.
По сути, в этот период потребности молодого специалиста сводятся к восполнению «пробелов» в овладении навыками и умениями, требуемыми для выполнения профессиональных задач. Ведомственная система повышения квалификации на этом этапе должна удовлетворить подобные потребности, одновременно с этим позволив освоить основы профессиональной деятельности.

Так, следователям, повышающим квалификацию в период первого года трудовой деятельности, должны преподаваться начала организации профессиональной деятельности, планирования труда.

Это позволит молодому специалисту эффективно организовать собственную деятельность с учетом имеющейся нагрузки, собственных качеств и других факторов.

Умения подобного рода невозможно выработать без реального распределения собственных сил, попыток планирования разных форм и видов деятельности. Указанные операции должны быть ориентированы на эффективное проведение отдельных профессиональных задач, а также их совокупности в различные временные периоды (планирование труда следователя на день, неделю, месяц и т. д.).

В этот же период формирование основ профессиональной квалификации требует освоения стандартных приемов, методов и средств разрешения конкретных практических задач. Отчасти отсутствие у практического работника навыков подобного рода действий обусловлено недостатками приобретения последним специальности в вузе.

Восполнение подобных пробелов может заключаться не только в предоставлении обучающемуся методических материалов о проведении конкретных операций, но и видеолекций с детальным обзором самого процесса и ньюансов реализации конкретных профессиональных операций. Например, ввиду значительного ограничения количества учебного времени, отводимого в ряде высших учебных заведений на дисциплину «криминалистика», большинство выпускников подобных заведений не обладают навыками осуществления простейших операций по поиску, исследованию и изъятию традиционных следов. Кроме простого просмотра практики выполнения указанных операций, для овладения навыками их 
осуществления в реальных условиях требуется многократное их повторение под контролем опытного инструктора-педагога.

Думается, что повышение квалификации молодого специалиста на указанном этапе может сочетать в себе различные формы обучения.

Сложная эпидемиологическая ситуация во всем мире и нашей стране повысила актуальность дистанционного обучения, расширила материальную базу всех без исключения высших учебных заведений и организаций, занимающихся послевузовским образованием. Подобные ситуации дали удачную возможность формирования основы дистанционного доступа заинтересованных специалистов в самостоятельном повышении собственной квалификации.

Однако и здесь есть ряд трудностей. Порой специфика производства отдельных профессиональных операций требует ограничения доступа к такой «служебной» информации. Электронная база с подобными видеолекциями требует ограниченного доступа к ней со стороны пользователей, специальных программных средств обеспечения контроля прохождения отдельных заданий слушателями, защищенных каналов к станциям, используемым самими обучаемыми.

Все это должно позволить сформировать у молодого специалиста умения производства с использованием стандартных приемов, методов и средств операций, ориентированных на разрешение типичных следственных ситуаций, с которыми чаще всего сталкивается следователь при выполнении профессиональных задач.

Помощь в формировании у следователя указанных навыков должны оказывать и более опытные коллеги, наставники следователя. Институт наставничества справедливо относится к эффективным инструментам формирования профессиональных качеств специалиста. Особый эффект он оказывает на этапе формирования профессиональной квалификации специалиста [2, с. 77].

Здесь следует отметить, что профессиональная деятельность следователя жестко регламентирована процессуальным законодательством. Это существенно уменьшает возможности внешнего участия сторонних лиц при выполнении конкретных практических операций. Если наставник молодого специалиста в области производства способен свободно принимать участие в контроле за процессом выполнения реальных практических операций, то участие наставника следователя требует выполнения ряда процессуальных решений. Осуществление контроля следователем (в том числе за планированием и организацией отдельных действий) ставит под угрозу тайну следствия, не допускает к участию сторонних лиц, не обладающих определенным процессуальным статусом.

Указанное, в свою очередь, определяет невозможность использования «живых» примеров в процессе повышения квалификации специалистов на этом этапе. Созданные же искусственно, хоть и приближенные к реальным, ситуации в процессе обучения снижают интерес к их разрешению со стороны обучаемых.

После получения следователем представлений об основах профессиональной деятельности должна следовать специализация его профессионального обучения.

Так, следующие сборы по повышению квалификации, на которые будет направляться специалист, могут быть ориентированы на особенности расследования отдельных категорий преступлений, с которыми сталкивается следователь в профессиональной деятельности.

Основной целью образовательной деятельности на этом этапе должно стать овладение следователем навыков разрешения типичных следственных ситуаций, формирующихся на различных этапах производства по уголовным делам об указанных преступлениях.

Выработка названных навыков и умений невозможна без практико-ориентированного обучения. Отработка разрешения тех или иных типичных следственных ситуаций требует активного участия педагога, осуществляющего контроль выполнения стандартных операций, планирования собственной деятельности следователем. Использование в указанном процессе дистанционных технологий также обладает определенной спецификой. Для формирования действенных навыков разрешения подобных ситуаций требуются специализированные программные средства, моделирующие приближенные к реальным условия выполнения отдельных действий. Использование же 
существующих на сегодняшний день средств выглядит достаточно неэффективным.

Так, в качестве средств, способствующих погружению обучаемого в приближенные к реальным условия моделируемых для него ситуаций, называют программный комплекс «Виртуальный осмотр места происшествия». Однако при всех достоинствах указанное средство формирует достаточно ограниченный подход следователя к разрешению поставленной задачи, для успешного прохождения которой требуется сбор определенного количества объектов без разбора методов и средств, используемых для их поиска. Думается, что для эффективного преодоления подобных трудностей требуется создание специальных программных средств, ориентированных на различные категории пользователей.

При подготовке же следователей, способных разрешать типовые следственные ситуации при расследовании традиционных преступлений, на сегодняшний день не обойтись без очного обучения указанных специалистов. Для помещения их в действительно приближенные к реальным ситуациям требуется поддержание в надлежащем, соответствующем современным требованиям виде криминалистических полигонов. Их многообразие и возможность трансформации позволит существенно расширить возможности повышения квалификационного уровня обучаемых. Одновременно с этим потребуется и увеличение финансирования ведомственных образовательных учреждений.

Для следователей, стремящихся к достижению уровня квалификации выше среднего, образовательный процесс должен строиться несколько иначе. На этом этапе повышения квалификации для них должны быть созданы приближенные к реальным, но обладающие большей сложностью следственные ситуации, разрешение которых потребует от обучаемого более высокого теоретического уровня, самостоятельности мышления. Ситуации подобного рода должны быть взяты из следственной практики, в мельчайших подробностях повторены.

Кроме всего прочего, для пользователей указанного уровня должен быть организован более широкий доступ к методическим и научно-практическим материалам, способству- ющим разрешению подобных трудностей. Названные источники могут относиться к литературе ограниченного использования, что также осложняет практическую реализацию. Возможности применения на указанном этапе дистанционных технологий также серьезно ограничены.

Наконец, на самом высоком уровне профессиональной квалификации располагаются специалисты, стремящиеся к доведению профессиональных качеств до уровня профессионального мастерства. Процесс обучения таких лиц, отличается индивидуальным подходом и требует тщательного планирования. Справедливо отмечается некоторыми авторами отсутствие необходимости каждого специалиста к освоению профессии на столь глубоком уровне [4, с. 42].

Для удовлетворения такого рода потребностей обучаемых должны быть сформированы достаточно массивные архивы уголовных дел, содержащих сложные следственные ситуации и опыт их практического разрешения с использованием нетрадиционных методов и средств. Сбор и обобщение следственной практики, содержащей уникальный опыт, также требует специальных программных средств хранения и получения доступа к ней. В разной степени при этом могут использоваться дистанционные технологии.

Нелишними на этом этапе станут возможности обмена опыта между отдельными специалистами, уже обладающими способностями разрешения указанных сложностей или являющихся специалистами высокой квалификации в решении отдельных задач раскрытия и расследования преступлений.

\section{Выводы}

Процесс повышения квалификации специалистов различных сфер требует учета особенностей формирования и закрепления профессиональных навыков и качеств, требующихся для эффективного решения профессиональных задач.

В связи с ограниченным объемом публикации не имеется возможности озвучить все особенности повышения квалификации следователей. Целью статьи в том числе является побуждение интереса специалистов в облас- 
ти методологии образовательной деятельности к процессу повышения квалификации следственных работников, выработке конкретных приемов и методов подготовки специалистов различных уровней с использованием активных и интерактивных форм обучения.

\section{СПИСОК ЛИТЕРАТУРЫ}

1. Долида, В. В. Использование инновационных методов при преподавании юридических дисциплин / В. В. Долида // Молодой ученый. - 2019. №20 (258). - С. 472-474.

2. Казачек, Е. Ю. Введение в должность молодого следователя - потребность следственной практики / Е. Ю. Казачек, Е. А. Киселев // Вестник Академии Следственного комитета Российской Федерации. - 2016. - № 4 (10). - С. 73-79.

3. Карагодин, В. Н. Соотношение процессов приобретения и повышения квалификации следователя / В. Н. Карагодин // Вестник Московской академии Следственного комитета Российской Федерации. - 2019. - № 2. - С. 158-163.

4. Кобзарь, К. П. Система специального образования в России как объект системно-целевого анализа / К. П. Кобзарь // Философия образования. - 2012. - № 4 (43). - С. 39-46.

5. Мандель, Б. Р. Профессионально-ориентированное обучение: проблематика и технологии : учеб. пособие для обучающихся в магистратуре / Б. Р. Мандель. - М. ; Берлин : ДиректМедиа, 2019. - 342 с.

6. Матяш, Н. В. Инновационные педагогические технологии. Проектное обучение : учеб. пособие / Н. В. Матяш. - М. : Академия, 2016. - 156 с.

\section{REFERENCES}

1. Dolida V.V. Ispolzovanie innovatsionnykh metodov pri prepodavanii iuridicheskikh distsiplin [The Use of Innovative Methods in Teaching Legal Disciplines]. Molodoi uchenyi [Young Scientist], 2019, no. 20 (258), pp. 472-474.

2. Kazachek E.Iu., Kiselev E.A. Vvedenie v dolzhnost molodogo sledovatelia - potrebnost sledstvennoi praktiki [Introduction to the Position of a Young Investigator - The Need for Investigative Practice]. Vestnik Akademii Sledstvennogo komiteta Rossiiskoi Federatsii, 2016, no. 4 (10), pp. 73-79.

3. Karagodin V.N. Sootnoshenie protsessov priobreteniia i povysheniia kvalifikatsii sledovatelia [Correlation of the Processes of Acquiring and Improving the Skills of an Investigator]. Vestnik Moskovskoi akademii Sledstvennogo komiteta Rossiiskoi Federatsii, 2019, no. 2, pp. 158-163.

4. Kobzar K.P. Sistema spetsialnogo obrazovaniia v Rossii kak obieekt sistemno-tselevogo analiza [The System of Special Education in Russia as an Object of System-Targeted Analysis]. Filosofiia obrazovaniia [Filosophy of Education], 2012, no. 4 (43), pp. 39-46.

5. Mandel B.R. Professionalno-orientirovannoe obuchenie: problematika i tekhnologii: uchebnoe posobie dlia obuchaiushchikhsia v magistrature [Professional-Oriented Training: Problems and Technologies: A Textbook for Students in the Master's Program]. Moscow, Berlin, Direkt-Media Publ., 2019. 342 p.

6. Matiash N.V. Innovatsionnye pedagogicheskie tekhnologii. Proektnoe obuchenie: uchebnoe posobie [Innovative Pedagogical Technologies. Project-Based Training: A Training Manual]. Moscow, Akademiya Publ., 2016. 156 p.

\section{Information About the Authors}

Vitaly F. Vasyukov, Doctor of Sciences (Jurisprudence), Associate Professor, Department of Criminal Law, Criminal Procedure and Criminalistics, Moscow State Institute of International Relations of the Ministry of Foreign Affairs of the Russian Federation, Prosp. Vernadskogo, 76, 119454 Moscow, Russian Federation; Professor, Department of Criminalistics and Preliminary Investigation in the Department of Internal Affairs, Orel Law Institute of the Ministry of Internal Affairs of Russia named after V.V. Lukyanov, Ignatova St, 2, 302027 Orel, Russian Federation, vvf009@yandex.ru, https://orcid.org/0000-0003-0743-5616

Alexey K. Shemetov, Senior Lecturer, Department of Criminalistics, Yekaterinburg Branch of Moscow Academy of the Investigative Committee of the Russian Federation, Shchorsa St, 18, 620142 Yekaterinburg, Russian Federation, shemetov_alexey@mail.ru, https://orcid.org/0000-0001-7519-4733 


\section{Информация об авторах}

Виталий Федорович Васюков, доктор юридических наук, доцент, доцент кафедры уголовного права, уголовного процесса и криминалистики, Московский государственный институт международных отношений (университет) МИД России, просп. Вернадского, 76, 119454 г. Москва, Российская Федерация; профессор кафедры криминалистики и предварительного расследования в ОВД, Орловский юридический институт МВД России им. В.В. Лукьянова, ул. Игнатова, 2, 302027 г. Орел, Российская Федерация, vvf009@yandex.ru, https://orcid.org/0000-0003-0743-5616

Алексей Константинович Шеметов, старший преподаватель кафедры криминалистики, Екатеринбургский филиал Московской академии Следственного комитета Российской Федерации, ул. Щорса, 18, 620142 г. Екатеринбург, Российская Федерация, shemetov_alexey@mail.ru, https://orcid.org/0000-0001-7519-4733 